\title{
A Fuzzy Multiobjective Programming Approach for Vendor Selection in Iron \& Steel Enterprise
}

\author{
Yuan Chen ${ }^{1}$, Zhi-Ping Fan ${ }^{1}$, Jun Lv $^{2}$, Jian-Yu Wang ${ }^{2}$ \\ ${ }^{1}$ School of Business Administration, Northeastern University, Shenyang, 110004, P. R. China \\ ${ }^{2}$ Baoshan Iron \& Steel Co., Ltd, Shanghai, 210900, P. R. China \\ chenyuan_neu@yahoo.com.cn
}

\begin{abstract}
The purpose of this paper is to study vendor selection problem with multi-vendor and multi-item in iron \& steel industry. Firstly, the native fuzziness, derived from some uncertainty information, of some parameters in decision-making objectives is analyzed. After that, a fuzzy multiobjective programming model is formulated, with procurement quantity as decision variable, minimizing the net cost, minimizing the quantity of raw materials rejected and delayed as fuzzy goals and buyer's demand, buyer's budget, buyer's technical prescription, vendors' supply elasticity, vendors' capabilities as constraints. Furthermore, the fuzzy optimization problem formulation is transformed into an equivalent formulation for the purpose of optimization after the membership functions of the fuzzy objectives are known, which is then solved for procurement decision making. Finally, an example is used to illustrate the applicability of the proposed approach.
\end{abstract}

Key words: Fuzzy multiobjective programming, Vendor selection, Iron \& steel enterprise

\section{Introduction}

The price of steel-iron material has been escalating far beyond our expectation in recent years and a trend in global sourcing have forced iron \& steel enterprise to promote cooperation with their raw material vendors. In addition, strategic partnership with better performed vendors should improve the performance in many aspects including reducing costs, continuously improving quality, reducing lead-time ${ }^{[1]}$. This brings us to deal with issues related to the selection of right vendors and corresponding quota allocations.

Much attention has been paid on the vendor selection problem (VSP). Gaballa firstly applied linear programming (LP) approach to select vendors and established a mixed integer programming (MIP) model for procurement of multi-item in Australian post office ${ }^{[2]}$. Sharma, Benton and Srivastava proposed an objective programming approach for VSP to attain satisfactory goals including price, quality and lead-time constrained by demand and budget $^{[3]}$. Byun applied analytical hierarchy process
(AHP) approach to select vendors in Korean automobiles $^{[4]}$. Liu, Ding, and Lall presented a data envelopment analysis approach for suppler selection with multiple objectives and Weber et al. also contributed $^{[5,6]}$. So far, there lacked enough literature on VSP in iron \& steel industry, some work relevant can be found in literatures $[7,8]$. It can be seen that most literatures deal with VSP by a certain approach, which tend to ignore the high degree of fuzziness and uncertainties of the environment in practical.

In a decision process of vendor selection, the required information is generally uncertain and different types of fuzziness exist at each decision stage. For example, values of many criteria are expressed in imprecise terms like 'very poor in late deliveries', 'hardly any rejected items' ${ }^{[9]}$, etc. As a result, to some extent, it will be far beyond the original intention of procurement decision makers when certain approach was used. Kuma, Vrat and Shankar proposed a fuzzy goal programming for VSP in a supply chain and make an original discussion ${ }^{[9]}$, which is based on the hypothesis that one item is only purchased from one vendor, taking no consideration of multi-vendor and multi-item. Hence such study has its limitation in practice to some extent. In order to reduce the risk of supplying and take the advantage of package supply, VSP considering multi-vendor and multi-item in a fuzzy environment is necessary in iron \& steel enterprise. However, how to incorporate information vagueness in VSP with multi-vendor and multi-item, to our knowledge, has not been stressed until now. In this paper, a fuzzy multiobjective programming approach for VSP (FMOP_VSP) is presented to deal with the problem.

This paper is organized as follows. Section 2 presents the VSP with multi-vendor and multi-item in iron \& steel enterprise. Section 3 describes the FMOP_VSP formulation by considering three important fuzzy objectives including minimizing the net total cost, minimizing the quantity of raw materials rejected, and minimizing the quantity of raw materials delivered lately. In Section 4, a solution approach for FMOP_VSP is proposed by solving the corresponding equivalent transformation. In Section 5, a case in a fuzzy environment is used to demonstrate the effectiveness of the proposed approach. Finally, some conclusions are drawn in section 6 . 


\section{Problem Description}

VSP with multi-vendor and multi-item in iron \& steel enterprise can be described as follows: suppose the demand for each item of materials is given in special period, the problem is to determine the practical purchasing quantity of each item from different vendors. Considering three important fuzzy objectives including minimizing the net total cost, minimizing the quantity of raw materials rejected, and minimizing the quantity of raw materials delivered lately subject to some constraints.

Firstly, owing to numerous types, large amount and high expenses of the material procurement, reducing the net cost is a primary objective that the iron \& steel enterprise would like to achieve. Beyond that, steel production is characterized as multiprocess, multi-phase and complicated course and the quality of the material means a lot to the production. Hence, the quantity of raw materials rejected, which shows the quality of the materials, should be another criterion for VSP. At last, in many circumstances material delay due to the conflict between the stability of vendors' throughputs and market's levity, which will affect the production severely, also should be considered.

Thus, the objective of material purchasing is to minimize the net cost, unqualified material quantity and possibly delayed material quantity subject to such constraints as material demands, budget, technical prescription, vendor's capability and supply flexibility, et al. However, it should be indicated that the purchasing environment of steel material is extraordinarily special. For instance, the rapid development of other highly energy consumption industry can pull the demands of coal, petroleum and electricity, thus leading to those resources being on edge. Then, fierce competition from interior industry can also run up such material price as ironstone. Moreover, other uncontrollable factors like jammed transportation and national macro-adjustment will also increase the uncertainty of material purchasing. In such decision making situations, high degree of fuzziness and uncertainties are involved in the data set and we proposed that the fuzzy objectives should be appropriate.

\section{Modeling}

\subsection{Assumptions and notation}

The VSP with multi-vendor and multi-item in a fuzzy environment is typically a multi-criteria decision problem. The following assumptions, index set, decision variable and parameters are considered. Assumptions

- One item can be purchased from different vendor.

- Over a fixed planning period, which could be a month, a quarter, or a year.

- Quantity discounts are not taken into consideration.

- Demands of items are constant and known.

Index set

$i \quad$ index for vendor, for all $i=1,2,3, \cdots, m$

$j \quad$ index for item, for all $j=1,2,3, \cdots, n$

Decision variable

$x_{i j} \quad$ order quantity of item $j$ from vendor $i$

Parameters

$p_{i j}$ price of per unit item $j$ of the ordered quantity from vendor $i$

$q_{i j} \quad$ percentage of the rejected units for item $j$ delivered by vendor $i$

$r_{i j}$ percentage of the late delivered units for item $j$ by vendor $i$

$D_{j}$ aggregate demand of item $j$

$B_{j}$ budget allocated to item $j$

$a_{g h}$ technical proportion between the order quantity of item $g$ and that of item $h$

$\xi_{i j}$ supply elasticity for item $j$ from vendor $i$

$E_{j}$ upper bound of the supply elasticity quantity of item $j$

$U_{i j}$ upper bound of the quantity of item $j$ available from vendor $i$

\subsection{Model formulation}

Not considering information vagueness, the VSP of multiobjective programming (MOP_VSP) can be formulated as follows:

$$
\begin{aligned}
\min Z_{1} & =\sum_{i=1}^{m} \sum_{j=1}^{n} p_{i j} x_{i j} \\
\min Z_{2} & =\sum_{i=1}^{m} \sum_{j=1}^{n} q_{i j} x_{i j} \\
\min Z_{3} & =\sum_{i=1}^{m} \sum_{j=1}^{n} r_{i j} x_{i j} \\
\text { s.t. } & \sum_{i=1}^{m} x_{i j} \geq D_{j}, j=1,2,3, \cdots, n \\
& \sum_{i=1}^{m} p_{i j} x_{i j} \leq B_{j}, j=1,2,3, \cdots, n \\
& \sum_{i=1}^{m} x_{i g}=a_{g h} \sum_{i=1}^{m} x_{i h} \\
& \sum_{i=1}^{m} \xi_{i j} x_{i j} \leq E_{j}, j=1,2,3, \cdots, n
\end{aligned}
$$




$$
\begin{aligned}
& x_{i j} \leq U_{i j}, i=1,2,3, \cdots, m, j=1,2,3, \cdots, n \\
& x_{i j} \geq 0, \quad i=1,2,3, \cdots, m, j=1,2,3, \cdots, n
\end{aligned}
$$

In this model, objective function ( $1 a)$ minimizes the net cost for all the items; objective function $(1 b)$ minimizes the net quantity of rejected items from the vendors, and objective function (1c) minimizes the net quantity of late delivered items from the vendors.

Constraint (1d) puts restrictions due to the overall demand of each item; constraint (1e) puts restrictions on budget amount for each item; constraint (1f) puts restrictions on technical proportion among some special items. For example, the proportion of molten iron to ironstone is $1: 2$; constraint $(1 g)$ incorporates flexibility needed with the vendors' quota; constraint $(1 h)$ put restrictions due to the maximum capacity of the vendors.

In real life situations, a lot of information required for selecting vendors are imprecise, vague or uncertain ${ }^{[9]}$. When vague information related to the objectives are presented then MOP_VSP can be formulated as FMOP_VSP, its formulation can be stated as follows:

Find $\boldsymbol{x}$

$$
\begin{array}{ll}
\text { to satisfy } & \mathrm{Z}_{\mathrm{k}} \cong \widetilde{\mathrm{Z}}_{\mathrm{k}}, \quad k=1,2,3 \\
\text { s.t. } & A x \propto b, \\
& x \geq 0,
\end{array}
$$

In this model, those objectives usually being fuzzy in real life situations are described as $\widetilde{Z}_{k}(k=1,2,3)$. In the formulations $(2 a)$, the symbol ' $\cong$ ' denotes the fuzziness of the goal. It represents the linguistic term 'about'. Constraints (1d) to (1h) are represented by $(2 b)$ and operator $\propto$ represents ' $\leqslant$ ' or ' $=$ ' or ' $\geqslant$ '. $x$ is decision variable vector.

\section{Solution approach}

Many solutions have been proposed for multiobjective programming problem $^{[9,11-12]}$. Illuminated by such studies, the solution in this paper firstly tries to get the aspiration level of the objective in problem one, which can be received by solving corresponding single objective programming problem separately. After that, a triangle membership function will be defined which will be the objective of problem two. Then, the value of decision variables would be gained through solving problem two.

The overall explanation of this solution is given as follows

Problem one

$$
\begin{array}{cl}
\min \mathrm{Z}_{\mathrm{k}} & k=1,2,3 \\
\text { s.t. } & A x \propto b \\
& x \geq 0
\end{array}
$$

In Problem one, objective function ( $3 a$ ) is the gathering of (1a) to (1c). Constraints (1d) to (1h) are represented by (3b) and operator $\propto$ represents ' $\leqslant$, or ' $=$ ' or ' $\geqslant$ '. This problem can be solved as a single objective programming problem. The value of objective $Z_{\mathrm{k}}(k=1,2,3)$ should approximately be the aspiration value of fuzzy objection $\widetilde{Z}_{\mathrm{k}}(k=1,2,3)$.

Using approach of Yang et al. ${ }^{[12]}$, the triangular membership function $u\left[Z_{k}\left(x_{i j}\right)\right]$ for the $k$ th fuzzy objective can be defined as follows:

$u_{\left[Z_{k}(x)\right]}=\left\{\begin{array}{lc}{\left[Z_{k}(x)-Z_{k}^{-}\right] /\left[\widetilde{Z}_{k}-Z_{k}^{-}\right],} & Z_{k}(x) \in\left[Z_{k}^{-}, \widetilde{Z}_{k}\right], \\ {\left[Z_{k}^{+}-Z_{k}(x)\right] /\left[Z_{k}^{+}-\widetilde{Z}_{k}\right],} & Z_{k}(x) \in\left[\widetilde{Z}_{k}, Z_{k}^{+}\right), \\ 0, & \text { otherwise, }\end{array}\right.$

where $\tilde{Z}_{\mathrm{k}}$ is the aspiration level of the $k$ th fuzzy objective, $Z_{k}^{-}$is a minimum limit of deviation to $\tilde{Z}_{\mathrm{k}}, Z_{k}^{+}$is a maximum limit of deviation to $\tilde{Z}_{\mathrm{k}}$, $u\left[Z_{k}(x)\right]$ is a strictly monotonically decreasing (or increasing) continuous function.

According to Bellman and Zadeh ${ }^{[10]}$, a fuzzy decision is a fuzzy set and is obtained by the intersection of the all the fuzzy sets representing the fuzzy objectives. The membership function of the fuzzy decision is given by

$$
u_{S}(x)=\bigcap_{k=1}^{3} u_{z_{k}}(x)=\min \left[\min _{k=1,2,3} u_{z_{k}}(x)\right]
$$

where $u_{s}\left(x_{i j}\right)$ and $u_{z_{k}}\left(x_{i j}\right)$ represent the membership functions of fuzzy decision set and the $k$ th fuzzy objective respectively.

An optimum element means selecting that element $x^{*}$ which has the highest degree of membership value to the fuzzy decision set:

$$
u_{S}\left(x^{*}\right)=\max _{x} u_{s}(x)=\max _{x} \min \left[\min _{k=1,2,3} u_{z_{k}}(x)\right]
$$

Based on that, another programming formulation defined to Problem two is given Problem two

$$
\begin{aligned}
\max \lambda & \\
\text { s.t. } & \lambda \leq u\left[Z_{k}(x)\right], \quad k=1,2,3 \\
& A x \propto b \\
& \lambda \in[0,1] \\
& x \geq 0
\end{aligned}
$$

where $u\left[Z_{k}(x)\right]$ is the triangular membership function for the $k$ th fuzzy objective; constraint $(7 c)$ is the same as constraint ( $3 b)$ in problem one.

Hence, the final result will be received by solving Problem two.

Now we summarize the complete solution procedures for the FMOP_VSP as follows:

Step 1: Establish the FMOP_VSP model.

Step 2: Select the first objective, solving Problem one and get its aspiration value.

Step 3: Select other objectives, repeat step2, until get all the aspiration value of the 
objectives.

Step 4: Determine the positive and negative value of the aspiration level.

Step 5: Define the membership function of each fuzzy objective.

Step 6: Convert Problem one to Problem two.

Step 7: Solving Problem two.

Step 8: Analyze the result, select right vendors and allocate quota to the vendors

\section{Example}

We present a small case whose data set is from a realistic situation. A certain iron \& steel enterprise need to select two material vendors from four candidates. The related information about the iron \& steel enterprise and vendors are displayed by Tab.1 and Tab. 2 respectively.

Tab.1 Information about iron \& steel enterprise

\begin{tabular}{cccc}
\hline Material & $D_{j}\left(10^{4}\right.$ ton $)$ & $B_{j}\left(10^{4} ¥\right)$ & $a_{g h}$ \\
\hline 1 & 8000 & 90000 & 2 \\
2 & 6000 & 60000 & 2 \\
\hline
\end{tabular}

Tab.2 Information of vendors

\begin{tabular}{ccccccc}
\hline \multirow{2}{*}{ Vendor } & Material & $p_{i j}$ & $q_{i j}$ & $r_{i j}$ & $\xi_{\mathrm{ij}}$ & $U_{i j}$ \\
\hline \multirow{2}{*}{1} & 1 & 11 & 0.06 & 0.12 & 0.5 & 10000 \\
& 2 & 7 & 0.04 & 0.09 & 0.3 & 15000 \\
\hline \multirow{2}{*}{2} & 1 & - & - & - & - & - \\
& 2 & 6 & 0.05 & 0.10 & 0.4 & 10000 \\
\hline \multirow{2}{*}{3} & 1 & 12 & 0.07 & 0.03 & 0.4 & 15000 \\
& 2 & 5 & 0.08 & 0.12 & 0.8 & 9000 \\
\hline \multirow{2}{*}{4} & 1 & 12 & 0.05 & 0.11 & 0.11 & 8000 \\
& 2 & - & - & - & - & - \\
\hline
\end{tabular}

According to the approach proposed in this paper, the result is:

$\lambda=0.336, \quad x_{11}=6000, x_{12}=3318.173, x_{22}=0$, $x_{31}=2000, x_{32}=3954.554, \quad \mathrm{x}_{41}=0$.

From the result, we can see, as for the first material, the enterprise should purchase 60 million tons from the first vendor, 20 million tons from the second vendor. Owing to the quote of the forth vendor is very high and the delayed situation is severe, as well as its supply is inflexible, we suggest not choose the forth vendor. As for the second material, the enterprise should purchase 33.18 million tons from vendor 1 and 39.54 million tons from vendor 3 .

\section{Conclusion}

Vendor selection is a vital work for material procurement in iron \& steel enterprise. We put forward a fuzzy multiobjective programming model for VSP based on fuzzy mathematics theory and multiobjective programming approach, which can solve the problem of material procurement with multi-vendor and multi-item in a fuzzy environment. This approach provides a better way to select vendors and optimize procurement quota allocation for decision makers. However, the proposed approach takes no accounts of quantity discounts and price discounts, which will accordingly be the key points of further research.

\section{References}

[1] Ghobadian, A. Stainer, T. Kiss, "A Computerized Vendor Rating System", Proceedings of the First International Symposium on Logistics, Nottingham, UK, 1993, pp. 321- 328 .

[2] Gaballa, Minimum, "Cost Allocation of Tenders", Operational Research Quarterly, vol. 25, no. 3, pp. 389-398, 1974.

[3] D. Sharma, W. C. Benton, R. Srivastava, "Competitive Strategy and Purchasing Decisions", Proceedings of the 1989 Annual Conference of the Decision Sciences Institute, pp. 1088-1090.

[4] D. Byun, "The AHP Approach for Selecting an Automobile Purchase model", Information and Management, vol. 38, pp. 289-297, 2001.

[5] F. Liu, F. Y. Ding, V. Lall, "Using Data Envelopment Analysis to Compare Suppliers for Supplier Selection and Performance Improvement", Supply Chain Management: An International Journal, vol. 5, no. 3, pp. 143-150, 2000.

[6] Weber, J. R. Current, A. Desai, "An Optimization Approach to Determining the Number of Vendors to Employ", Supply Chain Management: An International Journal, vol. 2, no. 5, pp. 90-98, 2000.

[7] R. N. Roy, K. K. Guin, "A Proposed Model of JIT Purchasing in an Integrated Steel Plant", International Journal of Production Economics, vol. 59, pp. 179-187, 1999.

[8] Z Gao, "Study on Optimization of Iron \& Steel Material Procurement and Column Generation Algorithm", Ph.D. dissertation, Management science. Chinese. Program, Univ. Northeastern, Shenyang, P.C.China, 2003.

[9] M. Kumar, P. Vrat, R. Shankar, "A Fuzzy Goal Programming Approach for Vendor Selection Problem in a Supply Chain", Computers and Industrial Engineering, vol. 46, pp. 69-85, 2004.

[10] R. E. Bellman, L. A. Zadeh, "Decision Making in a Fuzzy Environment", Management Science, vol. 17, pp. 141-164, 1970.

[11] J. J. Buckley, "Solving Possibilistic Linear Programming Problems", Fuzzy Sets and Systems, vol. 31, pp. 329-341, 1989

[12] T. Yang, J. P. Ignizio, H. J. Kim, "Fuzzy Programming with Nonlinear Membership Functions: Piecewise Linear Approximation", Fuzzy Sets and Systems, vol. 11, pp. 39-53, 1991. 